\title{
Identifikasi Jenis Jerawat Berdasarkan Tekstur Menggunakan GLCM dan Backpropagation
}

\author{
Yunita Fauzia Achmad ${ }^{1}$, Alivia Yulfitri², M. Bahrul Ulum ${ }^{3}$ \\ 1,2,3 Sistem Informasi, Universitas Esa Unggul
}

\begin{tabular}{ll}
\hline \hline Article Info & ABSTRAK \\
\cline { 2 - 3 } Article history: & Jerawat merupakan penyakit kulit yang mengakibatkan peradangan kronis \\
Received Jun $12^{\text {th }}, 2021$ & yang biasanya terdapat di wajah, leher, dan lengan. Terdapat berbagai jenis \\
Revised Aug $20^{\text {th }}, 2021$ & jerawat yaitu blackhead, whitehead, papula, pustula, nodul dan cystic. Telah \\
Accepted Aug $31^{\text {th }}, 2021$ & banyak upaya yang dilakukan untuk mengenali jenis jerawat, seperti tindakan \\
pemeriksaan langsung atau menggunakan alat skin analyzer, kedua cara ini & sangat tidak efektif dalam pengenalan jenis jerawat. Penelitian ini melakukan \\
Keyword: & identifikasi jenis jerawat berdasarkan tekstur dari jerawat, penelitian ini \\
Jerawat & menggunakan salah satu metode jaringan saraf tiruan yang yaitu algoritma \\
GLCM & backpropagation, dimana dengan menggunakan metode ini dapat melakukan \\
Backpropagation & identifikasi jenis jerawat dengan cepat. selain menggunakan algoritma \\
Jaringan Saraf Tiruan & backpropagation, penelitian ini juga melakukan ekstrasi ciri pada citra \\
Tekstur & jerawat dengan metode GLCM dan menghasilkan nilai ciri dengan \\
& menggunakan 4 fitur GLCM yaitu contrast, correlation, engery, dan \\
& homogeneity. Data yang digunakan pada penelitian ini dibagi menjadi dua \\
& yaitu data latih sebanyak 120 data dan data uji sebanyak 18 data. Tingkat \\
akurasi yang didapat dalam mengindentifikasi jenis jerawat mendapat \\
56,67\%, dimana nilai epoch yang digunakan adalah 10000 dengan nilai error \\
adalah 0,01. Nilai akurasi yang dihasilkan masih dibawah $70 \%$, terdapat \\
beberapa penyebab nilai akurasi kecil seperti data yang digunakan masih \\
kurang, bentuk pola dari jerawat yang memiliki kemiripan, sehingga jaringan \\
mengalami kesulitan dalam melakukan identifikasi jenis jerawat.
\end{tabular}

Corresponding Author: *First Author

Nama : Yunita Fauzia Achmad

Program Studi Sistem Informasi

Universitas Esa Unggul

Email: yunita@esaunggul.ac.id

\section{PENDAHULUAN}

Jerawat (acne vulgaris) merupakan penyakit kulit yang mengakibatkan peradangan kronis yang biasanya terdapat di wajah, leher, bahu, dada, punggung dan lengan atas dengan ditandai munculnya komedo, papula, nodul, dan pustula [1]. Jerawat merupakan penyakit kulit yang 80\% dialami oleh remaja laki - laki berusia 16 - 19 tahun dan remaja perempuan berusia 14 - 17 tahun. Menurut studi Golden Burden of Disease (GBD), jerawat $85 \%$ dapat dialami oleh dewasa muda yang berusia 12-25 tahun, penelitian di Jerman menemukan 64\% berusia 20-29 tahun dan 43\% berusia 30-39 tahun mempunyai jerawat, menurut catatan dermatologi kosmetik Indonesia penderita jerawat mencapai $60 \%$ pada tahun 2006, sedangkan pada tahun 2007 mengalami kenaikan mencapai $80 \%$ dan mencapai $90 \%$ pada tahun 2009 [2][3].

Berbagai upaya telah dilakukan dalam mendeteksi jenis jerawat dalam bidang kedokteran terdapat beberapa cara yang dilakukan seperti dengan cara tindakan pemeriksaan langsung menggunakan tangan namun cara ini merupakan cara yang konvensional dan menggunakan alat skin analyzer, tetapi kelemahan cara ini adalah harga untuk melakukan sekali pemeriksaan sangat mahal dan tidak semua klinik kecantikan memiliki alat tersebut [4]. 
Penelitian sebelumnya telah dilakukan peneliti tentang penerapan sistem pakar diagnosis penyakit jerawat berbasis web yang mengambil studi kasus di klinik kecantikan Navagreen Citra Raya Tangerang [5]. Penelitian ini membangun sistem pakar berbasis web didalam web tersebut terdapat sejumlah pertanyaan yang perlu dijawab user untuk mengetahui jenis jerawat yang diderita, kekurangan penelitian ini adalah ada beberapa pertanyaan yang dijawab user tidak sesuai dengan kondisi sebenarnya tentang jerawat yang diderita dan pada sistem pakar ini hanya memprediksi kemungkinan jenis jerawat yang diderita oleh user. Untuk mengatasi masalah tersebut peneliti mengembangkan penelitiannya menjadi identifikasi jenis jerawat berdasarkan tekstur. Tekstur merupakan pola atau karakteristik yang teratur maupun acak pada sebuah objek [6].

Pada penelitian ini selain melakukan analisis tekstur jerawat menggunakan metode GLCM ( grey level cooccurance matrix) dan juga melakukan identifikasi jenis jerawat menggunakan salah satu algoritma jaringan syaraf tiruan yaitu algoritma backpropagation. Metode GLCM merupakan metode ekstrasi fitur yang menunjukan metode statistik yakni orde kedua yang memberikan hasil lebih baik dalam melakukan ekstrasi karakteristik tekstur dan merupakan metode statistik orde kedua yang paling baik dalam melakukan ekstrasi fitur atau ciri, dan metode GLCM ini juga telah terbukti sangat powerful sebagai deskriptor ciri dalam merepresentasikan suatu karakteristik tekstur dari citra [6]. Algoritma backpropagation merupakan salah satu algoritma jaringan syaraf tiruan yang popular dengan menggunakan pembelajaran terawasi (supervised learning), algoritma backpropagation juga merupakan algoritma multilayer [7].

Penelitian tentang metode GLCM dan Algoritma Backpropagation telah banyak dilakukan seperti penelitian identifikasi "Acne Vulgaris" berdasarkan warna dan tekstur menggunakan klasifikasi JST backpropagation penelitian ini menggunakan metode ekstrasi ciri GLCM dan hasil akurasi yang didapat sebesar 65\% [8]. Penelitian lain seperti penelitian tentang identifikasi kesegaran daging sapi berdasarkan citranya dengan ekstrasi fitur warna dan tekstur menggunakan GLCM dan backpropagation sebagai klasifikasi, didapatkan tingkat akurasi sebesar 95,83\% [9].

\section{METODE PENELITIAN}

\subsection{Tahapan Identifikasi Jenis Jerawat}

Pada penelitian memiliki beberapa tahapan dalam melakukan identifikasi jenis jerawat, yaitu dapat dilihat pada Gambar 1, berilkut ini:

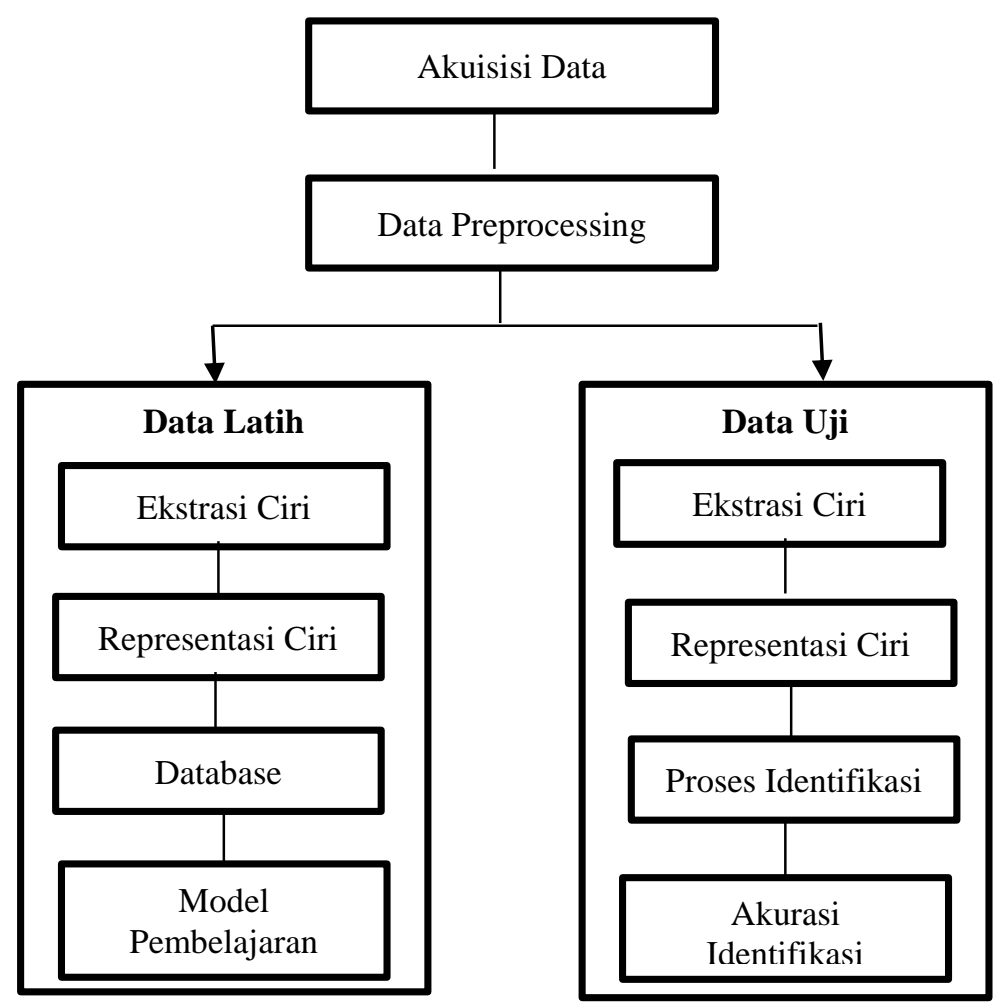

Gambar 1. Tahapan Identifikasi Jenis Jerawat 
Berdasarkan Gambar 1, dapat dilihat bahwa proses identifikasi jenis jerawat ini memiliki dua data yaitu data latih dan data uji. Setiap data dilakukan beberapa tahapan yang dilalui. Berikut penjelasan dari tahapan tahapan pada penelitian ini:

\section{Akuisisi Data}

Pengumpulan data yang dilakukan dengan mengambil foto tekstur jerawat sebanyak 138 data dari berbagai tekstur jerawat berdasarkan jenis - jenis jerawat, seperti papula, pustula, nodul, blackhead, whitehead, kistik. Pada akuisisi data dibagi menjadi dua yaitu data latih sebanyak 120 data dan data uji sebanyak 18 data.

\section{Data Pre-processing}

Pada setiap foto jerawat dilakukan resize citra, kemudian dilakukan proses grayscaling untuk mengubah foto asli menjadi citra keabuan dan juga melakukan segmentasi untuk mendapatkan area dari jerawat. Pada Gambar 2. Diperlihatkan perubahan citra asli yang diubah ke formt grayscale.

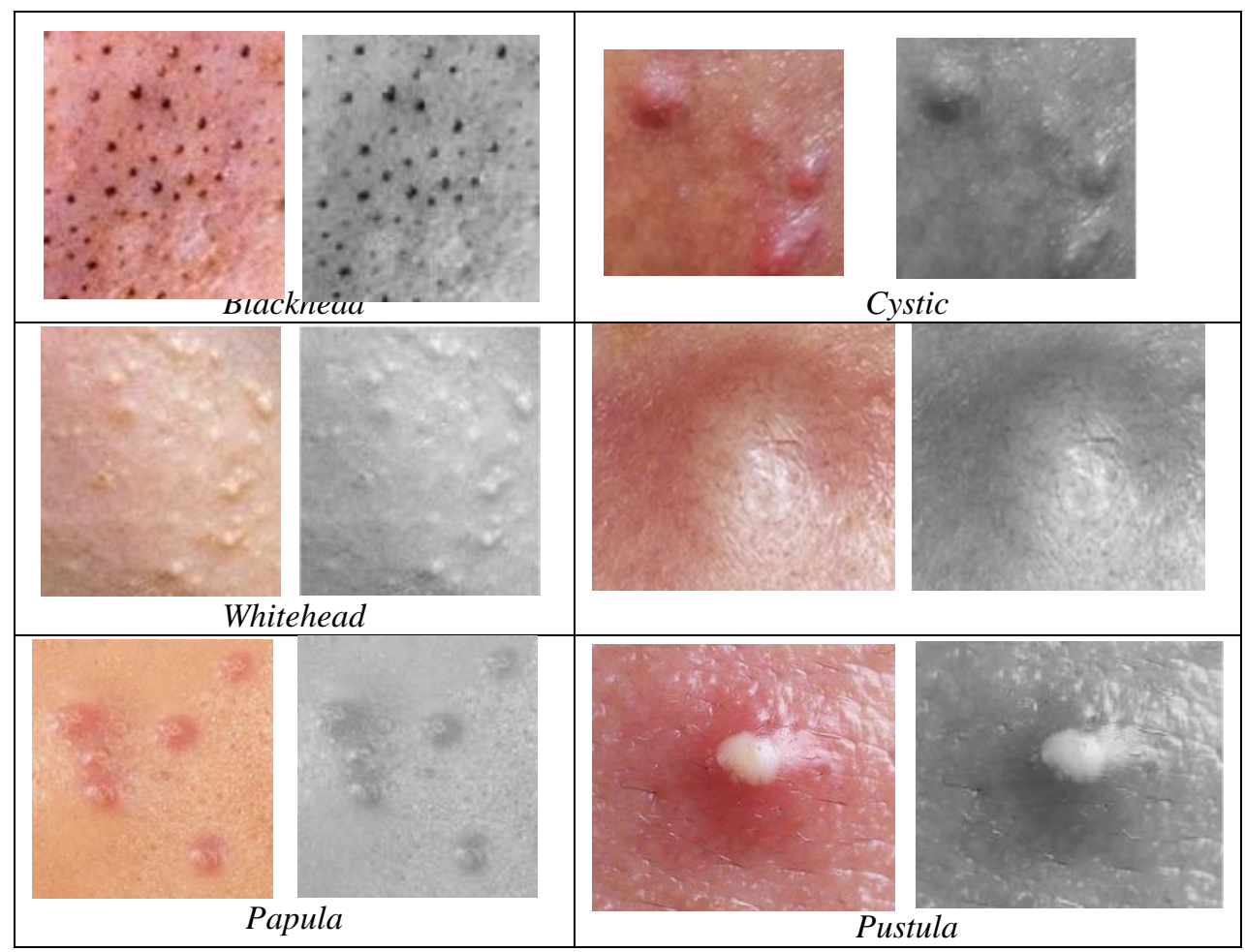

Gambar 2. Data Preprocessing Jenis Jerawat

\section{Ekstrasi Ciri}

Pada penelitian ini ekstrasi ciri atau ekstrasi fitur menggunakan GLCM dengan menggunakan 4 fitur GLCM yaitu contrast, correlation, energy dan entropy, berikut penjelasannya :

\section{GLCM}

Metode GLCM atau analisis tekstur merupakan salah satu metode untuk melakukan ekstrasi fitur suatu citra. GLCM adalah matriks persegi yang dapat menjelaskan sifat - sifat tertentu dengan distribusi spasial. GLCM menggunakan perhitungan tekstur pada orde kedua. Pada orde pertama, pengukuran tekstur menggunakan perhitungan stastistik didasarkan pada nilai piksel citra asli, seperti varians, dan tidak memperhatikan hubungan ketetanggan piksel. Sedangkan hubungan antar pasangan dua piksel citar asli diperhitungan pada orde kedua [10][6].

Koordinat pasangan piksel memiliki jarak d dari orientasi sudut $\theta$. Jarak direprestasikan dalam piksel dan sudut direpresentasikan dalam bentuk derajat. Pada orientasi sudut terdapat beberapat bentuk sudut yaitu $0^{\circ}, 45^{\circ}$, $90^{\circ}, 135^{\circ}$ dan jarak antar piksel sebesar 1 piksel [6]. Dapat dilihat pada Gambar 3 bentuk arah GLCM. 


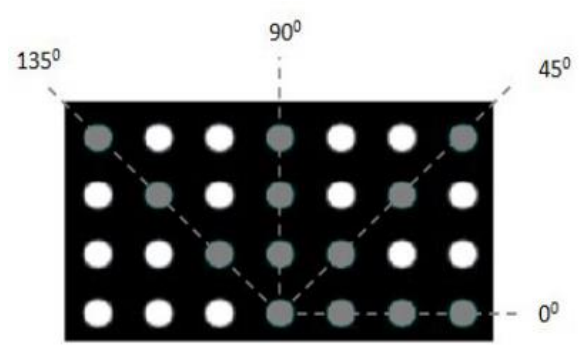

Gambar 3 Arah GLCM dengan sudut $0^{\circ}, 90^{\circ}, 45^{\circ}, 135^{\circ}[6]$

Untuk mendapatkan nilai piksel co-ocurensi dapat dilihat pada persamaan 1 dimana d adalah jarak antara dua piksel.

$$
P=\sum_{x-1}^{k} \sum_{y-1}^{k}\left\{\begin{array}{c}
1, \text { if } I(x, y)=i \text { and } I\left(x+d_{x} y+d_{y}\right)=1 \\
0, \text { lainnya }
\end{array}\right\}
$$

Tahapan yang dilakukan pada perhitungan ekstrasi fitur menggunakan metode GLCM adalah sebagai berikut:

1. Pembentukan matriks awal GLCM dari pasangan dua piksel yang berjajar sesuai dengan orientasi sudut yang digunakan $0^{0}, 45^{\circ}, 90^{\circ}$, atau $135^{\circ}$.

Contoh pembentukan matriks awal pada GLCM berbasis dua piksel, dapat dilihat pada Gambar 4.

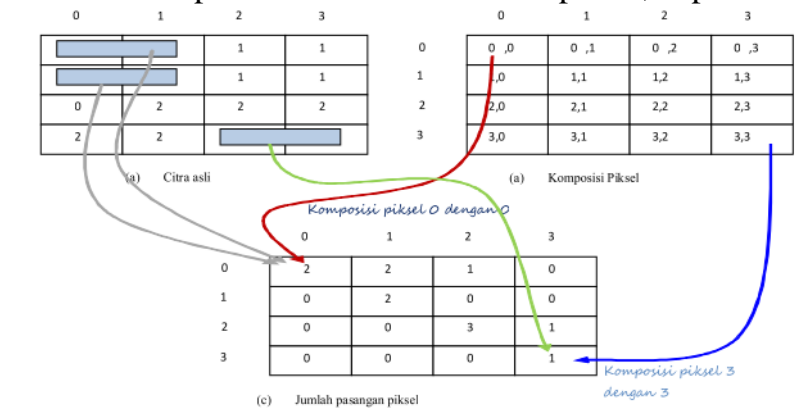

Gambar 4. Contoh Penentuan Matriks Awal pada GLCM [6]

2. Membentuk matriks yang simetris dengan menjumlahkan matriks awal GLCM dengan nilai transposnya. Pada Gambar 5 dapat dilihat contoh pembentukan matriks.

$$
\left[\begin{array}{llll}
2 & 2 & 1 & 0 \\
0 & 2 & 0 & 0 \\
0 & 0 & 3 & 1 \\
0 & 0 & 0 & 1
\end{array}\right]+\left[\begin{array}{llll}
2 & 0 & 0 & 0 \\
2 & 2 & 0 & 0 \\
1 & 0 & 3 & 0 \\
0 & 0 & 0 & 1
\end{array}\right]=\left[\begin{array}{llll}
4 & 2 & 1 & 0 \\
2 & 4 & 0 & 0 \\
1 & 0 & 6 & 1 \\
0 & 0 & 1 & 2
\end{array}\right]
$$

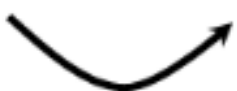

Gambar 5. Contoh Pembentukan Matriks [6]

3. Menormalisasi matriks GLCM dengan membagi setiap elemen matriks dengan jumlah pasangan piksel. Pada Gambar 6 dapat dilihat contoh nilai matriks GLCM yang telah dilakukan normalisasi dengan cara menjumlah semua pasangan piksel lalu dilakukan pembagian. 


$$
\left[\begin{array}{llll}
4 & 2 & 1 & 0 \\
2 & 4 & 0 & 0 \\
1 & 0 & 6 & 1 \\
0 & 0 & 1 & 2
\end{array}\right] \underset{\text { normalisasi }}{\longrightarrow}\left[\begin{array}{cccc}
\frac{4}{24} & \frac{2}{24} & \frac{1}{24} & 0 \\
\frac{2}{24} & \frac{4}{24} & 0 & 0 \\
\frac{1}{24} & 0 & \frac{6}{24} & \frac{1}{24} \\
0 & 0 & \frac{1}{24} & \frac{2}{24}
\end{array}\right]
$$

Gambar 6. Contoh Normalisasi Matriks GLCM [6]

4. Ekstrasi ciri atau fitur dengan menggunakan beberapa fitur dari GLCM yaitu :

1. Contrast

Contrast pada fitur GLCM menunjukkan ukuran penyebaran elemen - elemen matriks ciri. Jika letakmya jauh dari diagonal utama, nilai contrast besar. Pada persamaan 2 dijelaskan persamaan untuk menghitung nilai contrast, yaitu :

$$
\text { contrast }=\sum_{i} \sum_{j}(i-j)^{2} P_{(i, j)}
$$

2. Correlation

Correlation menyatakan ukuran ketergantungan linear derajat keabuan citra sehingga dapat memberikan petunjuk adanya struktur linear dalam citra. Pada persamaan 3 dijelaskan persamaan untuk menghitung nilai correlation, yaitu:

$$
\text { correlation }=\sum_{i} \sum_{j} \frac{\left(i-\mu_{i}\right)\left(j-\mu_{j}\right) P_{(i, j)}}{\sigma_{i} \sigma_{j}}
$$

3. Energy

Energy mengukur tentang keseragaman atau sering disebut angular second moment, energy akan bernilai tinggi ketika nilai piksel mirip dengan piksel yang lain, sebaliknya akan bernilai kecil yang berarti nilai dari GLCM normaliasai adalah heterogen. Pada persamaan 4 dijelaskan persamaan untuk menghitung nilai energy, yaitu:

$$
\text { energy }=\sum_{i} \sum_{j} P(i, j)^{2}
$$

4. Homogeneity

Homogeneity menunjukkan kehomogenan variasi intensitas dalam citra, homogeneity akan bernilai tinggi jika semua piksel mempunyai nilai yang uniform. Pada persamaan 5 dijelaskan persamaan untuk menghitung nilai homogeneity, yaitu:

$$
\text { homogeneity }=\sum_{i} \sum_{j} \frac{P_{(i, j)}}{1+|i-j|}
$$

\section{Representasi Citra}

Setiap nilai ciri yang telah didapatkan, maka akan dilabelkan sesuai dengan jenis jerawat yang dipakai seperti papula, blackhead, whitehead, pustula, nodul dan kistik.

\section{Database}

Pada data latih, nilai ciri yang telah direpressentasikan, maka akan disimpan kedalam sebuah database.

\section{Model pembelajaran}

Dilakukan model pembelajaran dengan menggunakan metode jaringan saraf tiruan yaitu metode backpropagation.

\section{Backpropagation}

Backpropagation merupakan salah satu algoritma jaringan syaraf tiruan yang menggunakan pembelajaran terbimbing (supervised learning), sehingga algoritma ini juga dapat digunakan untuk menyelesaikan permasalahan yang rumit. Dalam Pelatihan backpropagation memiliki tiga tahapan, seperti Feed forward dari pola input, perhitungan error dan penyesuaian bobot - bobot [7] . Dalam mempelajar pola input, pada jaringan syaraf tiruan menggunakan multilayer yang mampu mempelajari banyak inputan. Aliran jaringan multilayer terdiri dari input layer, hidden layer dan output layer. Input layer merupakan lapisan yang terdiri neuron atau unit - unit input, mulai dari unit 1 sampai unit input $\mathrm{n}$. hidden layer merupakan lapisan tersembunyi dari unit - unit tersembunyi sebagai unit tersembunyi, sedankan output layer merupakan lapisan 
yang terdiri dari unit - unit output mulai dari unit output 1 sampai unit output $\mathrm{n}$ [11]. Gambar 7 menunjukkan bentuk dari arsitektur backpropagation.

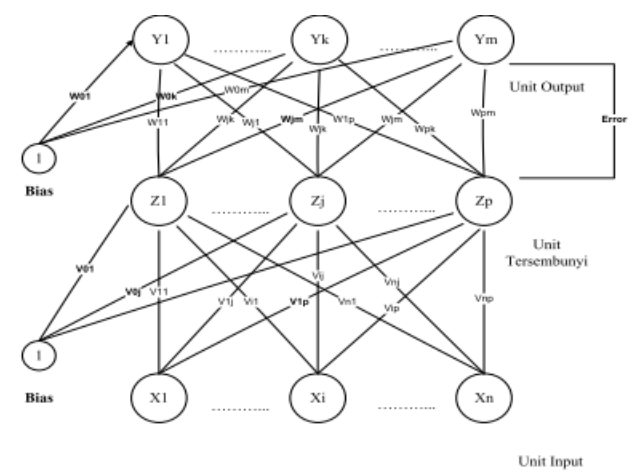

Gambar 7 Arsitektur Backpropagation [11]

\section{Proses Identifikasi}

Nilai - nilai yang berada di model pembelajaran dan yang telah berhasil dilakukan, diambil untuk dilakukan proses identifikasi jenis jerawat dan terdapat waktu komputasi dalam melakukan proses identifikasi. Waktu komputasi merupakan waktu yang dibutuhkan sistem untuk melakukan pengolahan data sampai didapatkan hasil atau keluaran yang diinginkan. Persamaan 6 merupakan persamaan dari waktu komputasi yang dilakukan pada penelitian ini :

$$
\text { waktu komputasi }=\text { waktu akhir }- \text { waktu awal }
$$

\section{Akurasi Identifikasi}

Pada tahapan akhir ini dilakukan perhitungan akurasi pada identifikasi jenis jerawat. Keakurasian jaringan syaraf tiruan dapat dilihat pada persamaan 7 , berikut ini :

$$
\text { akurasi }=\frac{\text { jumlah data benar }}{\text { jumlah data keseluruhan }} \times 100 \%
$$

\section{ANALISA DAN HASIL}

\subsection{Hasil Ekstrasi Fitur dengan GLCM}

Berikut ini adalah hasil nilai ciri yang terdiri dari 4 fitur nilai GLCM beserta nilai rata - ratanya pada data jerawat. Tabel 1 sampai dengan tabel 6 merupakan tampilan nilai ciri dari enam jenis jerawat.

Tabel 1. Nilai Ciri Nodul

\begin{tabular}{llccrr} 
& $\mathbf{0}^{\mathbf{0}}$ & $\mathbf{4 5}^{\mathbf{0}}$ & $\mathbf{9}^{\mathbf{0}}$ & $\mathbf{1 3 5}^{\mathbf{0}}$ & \multicolumn{1}{c}{ Rata - rata } \\
\hline Contrast & 0.16341 & 0.17805 & 0.15479 & 0.19852 & 0.17369 \\
Correlation & 0.87623 & 0.86535 & 0.88309 & 0.84986 & 0.86863 \\
Energy & 0.25473 & 0.24891 & 0.25954 & 0.23995 & 0.25078 \\
Homogeneity & 0.92214 & 0.91568 & 0.92627 & 0.90591 & 0.9175 \\
\hline
\end{tabular}

Tabel 2. Nilai Ciri Blackhead

\begin{tabular}{llrrrr} 
& $\mathbf{0}^{\mathbf{0}}$ & $\mathbf{4 5}^{\mathbf{0}}$ & $\mathbf{9}^{\mathbf{0}}$ & $\mathbf{1 3 5}^{\mathbf{0}}$ & \multicolumn{1}{c}{ Rata - rata } \\
\hline Contrast & 0.10638 & 0.1453 & 0.11824 & 0.1329 & 0.12571 \\
Correlation & 0.67755 & 0.55682 & 0.64123 & 0.59462 & 0.61755 \\
Energy & 0.63445 & 0.6084 & 0.62522 & 0.61585 & 0.62098 \\
Homogeneity & 0.94776 & 0.92993 & 0.94193 & 0.93494 & 0.93864 \\
\hline
\end{tabular}




\begin{tabular}{|c|c|c|c|c|c|}
\hline \multicolumn{6}{|c|}{ Tabel 3. Nilai Ciri Papula } \\
\hline & $\mathbf{0}^{\mathbf{0}}$ & $\mathbf{4 5}^{0}$ & $9^{0}$ & $135^{0}$ & Rata - rata \\
\hline Contrast & 0.088634 & 0.10229 & 0.091663 & 0.12312 & 0.10143 \\
\hline Correlation & 0.67103 & 0.62103 & 0.66054 & 0.54389 & 0.62412 \\
\hline Energy & 0.65737 & 0.64575 & 0.65424 & 0.62951 & 0.64672 \\
\hline Homogeneity & 0.95568 & 0.94886 & 0.95417 & 0.93844 & 0.94929 \\
\hline
\end{tabular}

\begin{tabular}{llcccr} 
& \multicolumn{2}{c}{ Tabel 4, Nilai Ciri Cystic } \\
& $\mathbf{0}^{\mathbf{0}}$ & $\mathbf{4 5}^{\mathbf{0}}$ & $\mathbf{9}^{\mathbf{0}}$ & $\mathbf{1 3 5}^{\mathbf{0}}$ & Rata - rata \\
\hline Contrast & 0.20608 & 0.23475 & 0.18799 & 0.24348 & 0.21808 \\
Correlation & 0.80271 & 0.77234 & 0.81983 & 0.76489 & 0.78994 \\
Energy & 0.28331 & 0.27071 & 0.29379 & 0.26784 & 0.27891 \\
Homogeneity & 0.89828 & 0.88453 & 0.90698 & 0.88076 & 0.89264 \\
\hline
\end{tabular}

\begin{tabular}{lrcccr} 
& \multicolumn{2}{c}{ Tabel 5 Nilai Ciri Pustula } \\
& $\mathbf{0}^{\mathbf{0}}$ & $\mathbf{4 5}^{\mathbf{0}}$ & $\mathbf{9}^{\mathbf{0}}$ & $\mathbf{1 3 5}^{\mathbf{0}}$ & Rata - rata \\
\hline Contrast & 0.13521 & 0.17398 & 0.16534 & 0.20431 & 0.16971 \\
Correlation & 0.91571 & 0.89153 & 0.89687 & 0.87262 & 0.89418 \\
Energy & 0.2804 & 0.26424 & 0.26728 & 0.24981 & 0.26543 \\
Homogeneity & 0.93256 & 0.91403 & 0.91778 & 0.89893 & 0.91582 \\
\hline
\end{tabular}

\begin{tabular}{lrrrrr} 
& \multicolumn{2}{c}{ Tabel 6. Nilai Ciri Whitehead } \\
& $\mathbf{0}^{\mathbf{0}}$ & $\mathbf{4 5}^{\mathbf{0}}$ & \multicolumn{1}{c}{$\mathbf{9}^{\mathbf{0}}$} & $\mathbf{1 3 5}^{\mathbf{0}}$ & \multicolumn{1}{c}{ Rata - rata } \\
\hline Contrast & 0.1676 & 0.18413 & 0.15122 & 0.19957 & 0.17563 \\
Correlation & 0.87705 & 0.86514 & 0.88956 & 0.85378 & 0.87138 \\
Energy & 0.24033 & 0.232 & 0.24692 & 0.22763 & 0.23672 \\
Homogeneity & 0.91708 & 0.90893 & 0.92465 & 0.90288 & 0.91339 \\
\hline
\end{tabular}

\subsection{Tampilan Program Identifikasi Jenis Jerawat}

Pada penelitian ini, dikembangkan program identifikasi jenis jerawat dengan menggunakan perangkat lunak Matlab. Gambar 8 menjelaskan tampilan UI (user interface) aplikasi identifikasi jenis jerawat.

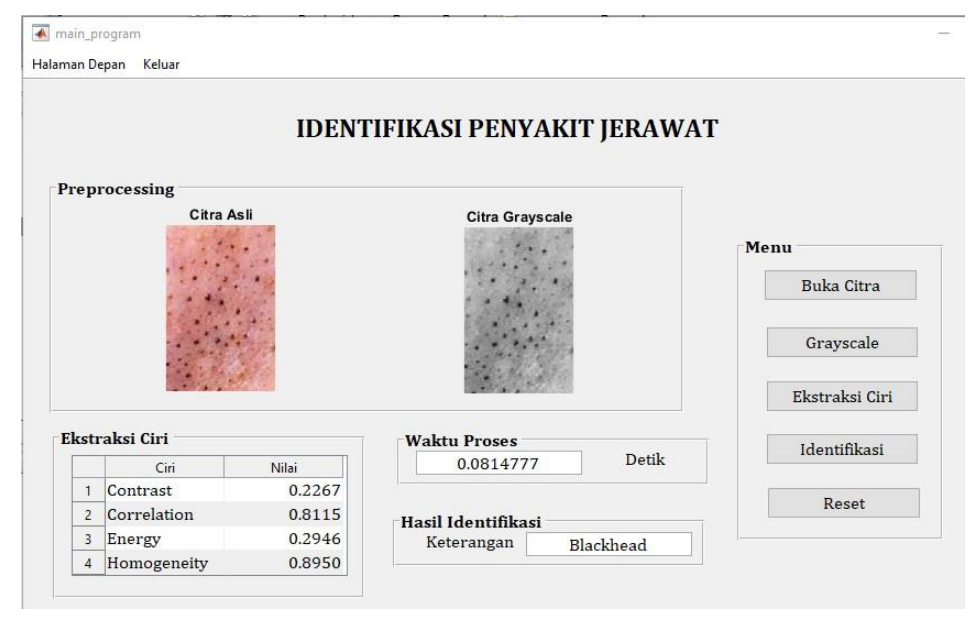

Gambar 8. Tampilan Sistem Identifikasi Jenis Jerawat

Pada sistem identifikasi jenis jerawat memiliki 5 fitur yaitu buka citra, grayscale, ekstrasi ciri, identifikasi, dan reset. Fitur buka citra adalah fitur yang dipergunakan untuk mengambil citra asli pada tempat penyimpanan, fitur grayscale adalah fitur yang yang digunakan untuk mengubah citra asli menjadi warna keabuan, setelah dilanjutkan dengan melakukan ekstrasi ciri dimana akan muncul nilai - nilai fitur GLCM yang terdiri dari contrast, correlation, energy dan homogeneity untuk citra yang dimasukkan kedalam sistem, setelah nilai fitur ekstrasi citra didapat, dilakukan identifikasi jenis jerawat dengan menambahkan waktu proses / waktu komputasi. Dan terakhir fitur reset yang digunakan untuk menghapus semua data didalam sistem tersebut. 


\subsection{Hasil Akurasi Identifikasi Jenis Jerawat}

Dengan menggunakan algoritma backpropagation, akurasi yang dihasilkan dalam melakukan identifikasi jerawat berdasarkan teksturnya mendapatkan akurasi sebesar 56,67\%.

\section{KESIMPULAN}

Kesimpulan yang didapat dari penelitian ini adalah bawah metode GLCM dalam melakukan ekstrasi ciri telah berhasil dan untuk identifikasi jerawat dengan algoritma backpropagation mendapatkan nilai akurasi sebesar 56,67\% dengan nilai epoch yang digunakan adalah 10000 dan learning rate yang digunakan 0,01. Nilai akurasi yang didapat masih dibawah $70 \%$ dari nilai akurasi yang diharapkan. Terdapat beberapa penyebab nilai akurasi kecil seperti data yang digunakan masih kurang, bentuk pola dari jerawat yang memiliki kemiripan, sehingga jaringan mengalami kesulitan dalam melakukan identifikasi jenis jerawat.

\section{REFERENSI}

[1] R. T. Lestari et al., "Perilaku Mahasiswa Terkait Cara Mengatasi Jerawat," J. Farm. Komunitas, vol. 8, no. 1, p. 15, 2020, doi: 10.20473/jfk.v8i1.21922.

[2] H. T. Sibero, A. Sirajudin, and D. Anggraini, "Prevalensi dan Gambaran Epidemiologi Akne Vulgaris di Provinsi Lampung The Prevalence and Epidemiology of Acne Vulgaris in Lampung," J. Farm. Komunitas, vol. 3, no. 2, pp. 62-68, 2019, [Online]. Available: https://e-journal.unair.ac.id/JFK/article/view/21922.

[3] R. N. Afriyanti, “Akne Vulgaris Pada Remaja,” Med. Fac. Lampung Univ., vol. 4, no. 6, pp. 102-109, 2015.

[4] K. Muzdalifah, Nava; Adi, "Identifikasi Jenis Jerawat Dengan Wavelet Haar Dan Jaringan Syaraf Tiruan Propagasi Balik," Youngster Phys. J., vol. 5, no. 4, pp. 171-178, 2016.

[5] E. D. Pangestu and Y. F. Achmad, "Penerapan Sistem Pakar Diagnosis Jerawat Berbasis Web (Studi Kasus: Navagreen Citra Raya)," Rekayasa, vol. 13, no. 2, pp. 103-111, 2020, doi: 10.21107/rekayasa.v13i2.5860.

[6] Neneng, K. Adi, and R. R. Isnanto, "Support Vector Machine Untuk Klasifikasi Citra Jenis Daging Berdasarkan Tekstur Menggunakan Ekstraksi Ciri Gray Level Co-Occurrence Matrices ( GLCM )," J. Sist. Inf. Bisnis, vol. 01, pp. 1-10, 2016, doi: 10.21456/vol6iss1pp1-10.

[7] M. Najwa, B. Warsito, and D. Ispriyanti, "Pemodelan Jaringan Syaraf Tiruan Dengan Algoritma One Step Secant Backpropagation Dalam Return Kurs Rupiah Terhadap Dolar Amerika Serikat," J. Gaussian, vol. 6, no. 1, pp. 61-70, 2017.

[8] M. Elisiana, U. D. Rosiani, and K. S. Batubulan, "Identifikasi ' Acne Vulgaris ' berdasarkan Fitur Warna dan Tekstur Menggunakan Klasifikasi JST Backpropagation,” J. Inform. polinema, vol. 7, no. 2, pp. 7-12, 2021.

[9] R. A. Asmara, D. Puspitasari, S. Romlah, Q. H, and R. Romario, "Identifikasi Kesegaran Daging Sapi berdasarkan Citranya dengan Ekstrasi Fitur Warna dan Teksturnya menggunakan Metode Gray Level Co-occurance Matrix," vol. 9, 2017.

[10] M. Ramadhani, H. B. D. K, and Suprayogi, "Klasifikasi Jenis Jerawat Berdasarkan Tekstur dengan Menggunakan metode GLCM," vol. 5, no. 1, pp. 870-876, 2018.

[11] S. Nurmuslimah, "Implementasi Metode Backpropagation Untuk Mengidentifikasi Jenis Biji Kakao Yang Cacat Berdasarkan Bentuk Biji,” J. Ilm. NERO, vol. Vol. 2, No, no. 2, pp. 91-98, 2016. 